\title{
Durability of dielectric fluids for concentrating photovoltaic systems
}

\author{
M. Victoria , S. Askins, C. Domínguez, I. Antón, G. Sala
}

\begin{abstract}
A B S T R A C T
Several dielectric fluids that might be used for immersing optics are analyzed in this paper. Their transmittances, both before and after an accelerated exposure to ultraviolet (UV) radiation equivalent to several years under real sun, are presented. In addition, the photocurrent losses caused by the decrease in transmittance experienced by each fluid are estimated for current III-V multijunction (MJ) solar cells. The most stable fluids were found to be paraffin and silicone oils whose transmittances remained practically unaltered after a UV dosage equivalent to 3 vears of AM1.5D radiation.
\end{abstract}

\section{Introduction}

Several concepts for concentrating photovoltaic (CPV) systems that include a fluid as an optical component have been proposed [1-3]. Some of them use the fluid to increase the concentrator optical performance: in the first place, by surrounding the solar cell with a medium whose refractive index is higher than one, the attainable concentration-acceptance angle product (CAP) [4] increases, and in the second place, the fluid acts as a refractive index adapter reducing Fresnel losses at the solar cell entrance and the front transparent cover. Other strategies to increase efficiency consist in using the fluid to reduce the solar cell temperature by natural or forced convection. An additional idea could be to use a dielectric fluid to fill secondary optical elements (SOE) or as an optical coupler between the solar cell and a glass SOE. Moreover, the reduction of surface recombination when the solar cell is immersed in certain fluids has been pointed out by several authors [5-7] as a path to increase efficiency, however its effect on multijunction (MJ) solar cells is not very significant.

Besides showing high transmittance for all the wavelengths useful for MJ solar cells, suitable fluids should withstand longtime outdoor exposure without significant degradation. In order to analyze fluids reliability, they were exposed to low concentrated UV irradiance in a test chamber built on purpose for these experiments (described in Section 4). Transmittances of the fluid samples were measured initially and after receiving a UV dosage equivalent to several years of 1 -sun irradiance. In addition, an analysis of the photocurrent losses that MJ solar cells would experience as a consequence of the decreased transmission in the fluids can be found in Section 6 .

\section{Fluids under test}

Based on their transparency at wavelengths within the visual range, up to 12 fluids were identified as candidates to be a part of a CPV system. The stability of seven of them under accelerated UV degradation tests was analyzed: glycerol, ethylenglycol, three kinds of paraffin oils, a synthetic hydrocarbon, and silicone oil. Paraffin oil, also known as mineral oil or nujol, consists of acyclic and saturated hydrocarbons chains containing between 5 and 20 carbon atoms. The most significant difference between first and second paraffin oils (identified as paraffin $A$ and $B$ across the text and figures) is their viscosity. They were obtained by a different refining process than paraffin $C$ [8]. Therminol is a synthetic hydrocarbon specifically designed as a heat transfer fluid by the company Solutia. The physical properties of all of them are summarized in Table 1 which also includes five extra candidates (deionized (DI) water, ethyl acetate, isopropyl alcohol, ethanol, and methanol) that have not been tested under UV light yet. Most of the physical data are accessible in the literature but this paper tries to review the existing information related to the fluids optical properties from the point of view of using them in a photovoltaic system. All the fluids refractive indices are between 1.33 and 1.48 (at the sodium line; $589.3 \mathrm{~nm}$ ) (Fig. 1) and their Abbe numbers are between 45 and 62 (but for the synthetic hydrocarbon which optical properties are not known). Refractive indices dependence with temperature has been carefully analyzed. If temperature distribution is not homogenous a refractive index gradient appears in the fluid. This might deflect the light travelling through the fluid and limit the attainable concentration. DI water has the lower 
Table 1

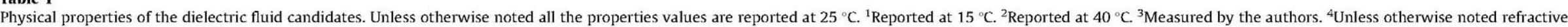
index is reported at $589.3 \mathrm{~nm} .{ }^{4}$ Reported at $18{ }^{\circ} \mathrm{C}$. ${ }^{5}$ Reported at $20^{\circ} \mathrm{C}$. ${ }^{6}$ Reported at $19{ }^{\circ} \mathrm{C}$.

\begin{tabular}{|c|c|c|c|c|c|c|c|c|c|c|c|c|c|c|c|c|c|c|c|c|}
\hline \multirow[b]{2}{*}{ Density $\left(\mathrm{kg} \mathrm{m}^{-3}\right)$} & \multicolumn{2}{|l|}{ Glycerol } & \multicolumn{2}{|c|}{ Ethylenglycol } & \multicolumn{2}{|l|}{ Paraffin $A / B / C$} & \multicolumn{2}{|c|}{ Synthetic hydrocarbon } & \multicolumn{2}{|l|}{ Silicone oil } & \multicolumn{2}{|c|}{ DI water } & \multicolumn{2}{|c|}{ Ethyl acetate } & \multicolumn{2}{|c|}{ Isopropyl alcohol } & \multicolumn{2}{|c|}{ Methanol } & \multicolumn{2}{|l|}{ Ethanol } \\
\hline & 1256 & [9] & 959 & [9] & $850 / 870 / 834^{1}$ & [10] & 755 & [11] & 913 & [12] & 997 & [9] & 897 & [3] & 786 & [3] & 787 & [9] & 787 & [9] \\
\hline Viscosity (10 $0^{3}$ Pas $)$ & 934 & [9] & 16.1 & [9] & $17^{2} / 65^{2} / 10^{2}$ & [10] & 0.9286 & [11] & 4.565 & [12] & 0.89 & [9] & 0.43 & [3] & 2 & [3] & 0.544 & [9] & 1.074 & [9] \\
\hline Th. cond. (W $\mathrm{m}^{-1} \mathrm{~K}^{-1}$ ) & 0.292 & [9] & 0.256 & [9] & 0.15 & [13] & 0.11 & [11] & 0.13 & [12] & 0.6071 & [9] & 0.14 & [3] & 0.16 & [3] & 0.2 & [9] & 0.169 & [9] \\
\hline Spec. Heat $\left(\mathrm{J} \mathrm{kg}^{-1} \mathrm{~K}^{-1}\right)$ & 2380 & [9] & 2390 & [9] & 2130 & [13] & 2180 & [11] & 1550 & [3] & 4181 & [9] & 1932 & [3] & 2721 & [3] & 2530 & [9] & 2440 & [9] \\
\hline Thermal ex. $\left(10^{3} \mathrm{~K}^{-1}\right)$ & 0.53 & [9] & 0.566 & [9] & $0.68^{3}$ & & 0.112 & [11] & 1.05 & [12] & 0.4087 & [9] & 0.43 & [3] & 2 & [3] & 1.19 & [9] & 1.1 & [9] \\
\hline Boiling point $\left({ }^{\circ} \mathrm{C}\right)$ & 182 & [14] & 196 & [14] & 112 & [14] & 180 & [11] & 200 & [12] & 100 & [9] & 76.5 & [14] & 82 & [14] & 64.7 & [14] & 78.3 & [14] \\
\hline Freezing point $\left({ }^{\circ} \mathrm{C}\right)$ & 20 & [14] & -13 & [14] & $-6 /-9 /-14$ & [10] & -50 & [11] & -70 & [12] & 0 & [9] & -84 & [14] & -89.5 & [14] & -98 & [14] & -114.1 & [14] \\
\hline Refractive Index 4 & 1.4746 & [15] & 1.4318 & [15] & $1.475^{3}$ & & & & 1.3960 & [12] & 1.3330 & [15] & 1.3730 & [3] & 1.3770 & [3] & 1.3288 & [15] & 1.3611 & [15] \\
\hline Abbe number & $61^{4}$ & [16] & $62^{5}$ & [17] & $53^{6}$ & {$[18]$} & & & $53^{6}$ & [18] & 50 & [19] & & & 45 & [20] & $61^{4}$ & [16] & $60^{4}$ & [16] \\
\hline$\delta n / \delta T\left(\mathrm{~K}^{-1}\right)$ & -230 & [15] & -270 & [15] & $400^{3}$ & [13] & & & & & -98 & [15] & -460 & [13] & -530 & [13] & -405 & [15] & -405 & [15] \\
\hline Dielectric constant & 46.5 & [9] & 41.4 & [9] & 2.2 & [13] & & & 2.7 & [3] & 80.1 & [9] & & [3] & 18.3 & [3] & 33 & [9] & 25.3 & [9] \\
\hline Formula & $\mathrm{C}_{3} \mathrm{H}_{8} \mathrm{O}_{3}$ & & $\mathrm{C}_{2} \mathrm{H}_{6} \mathrm{O}_{2}$ & & $\mathrm{C}_{\mathrm{n}} \mathrm{H}_{2 \mathrm{n}+2}$ & & $\mathrm{C}_{11} \mathrm{H}_{24}$ & & $\left(\mathrm{Si}\left(\mathrm{CH}_{3}\right)_{2} \mathrm{O}\right)_{\mathrm{n}}$ & & $\mathrm{H}_{2} \mathrm{O}$ & & $\mathrm{C}_{4} \mathrm{H}_{8} \mathrm{O}_{2}$ & & $\mathrm{C}_{3} \mathrm{H}_{8} \mathrm{O}$ & & $\mathrm{CH}_{4} \mathrm{O}$ & & $\mathrm{C}_{2} \mathrm{H}_{6} \mathrm{O}$ & \\
\hline
\end{tabular}

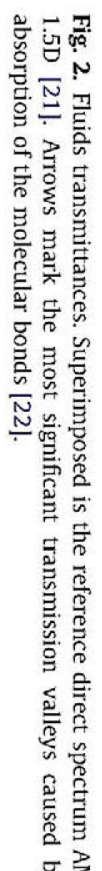

$T$, transmitance

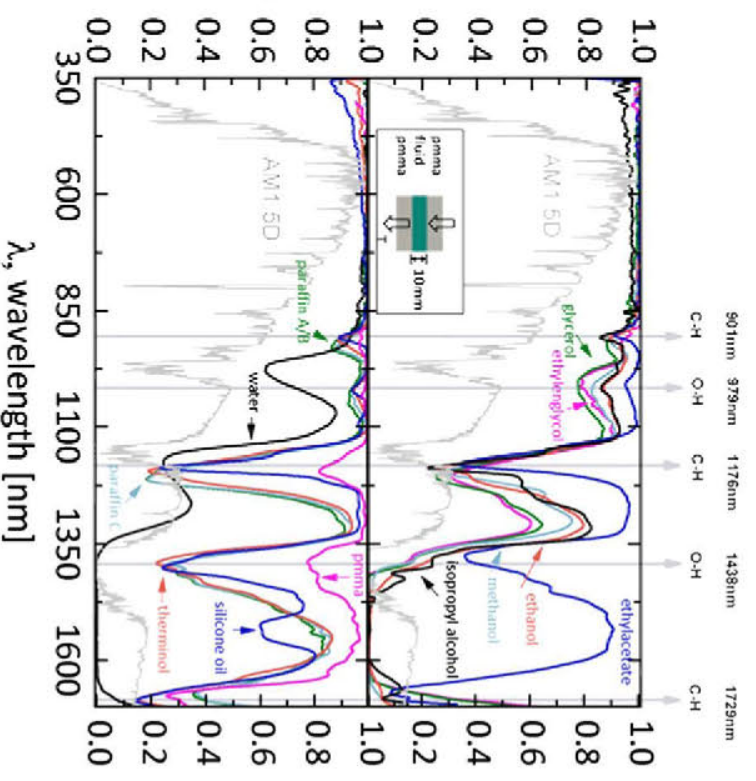

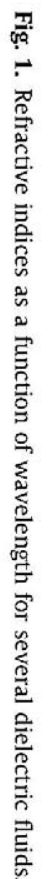

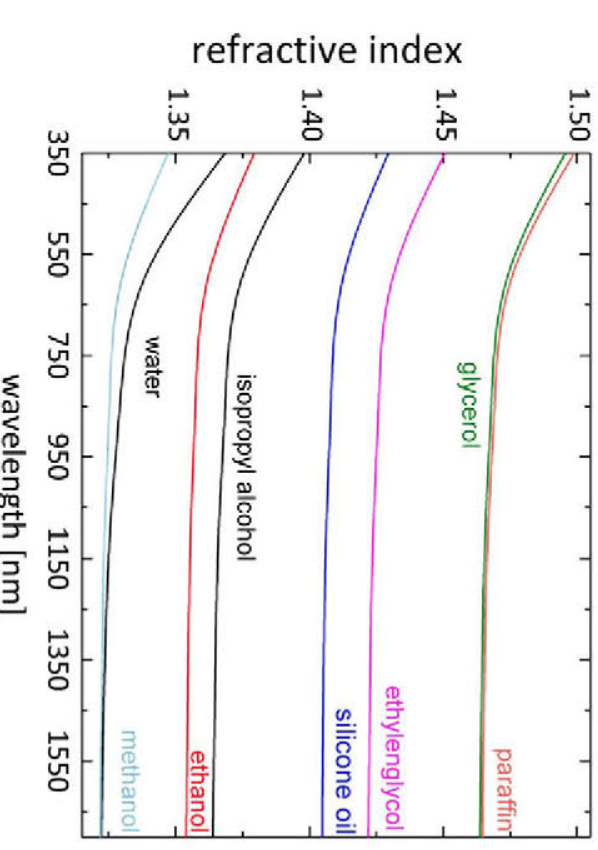

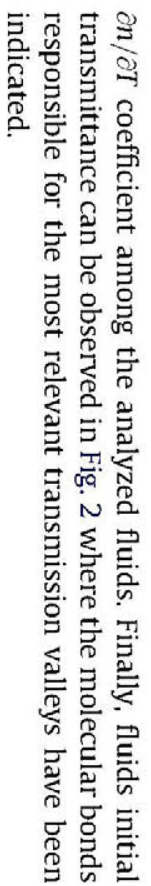


below $55{ }^{\circ} \mathrm{C}$ at every moment. However, the cuvettes top surfaces are kept free of water to avoid UV filtering.

The samples plane is located $15 \mathrm{~cm}$ bellow the lamp which creates the irradiance spatial distribution shown in Fig. 4. To quantify the radiation received by each sample two sensors were used. First, a photodiode sensitive to UVC was used to check the absence of UVC radiation (between 200 and $280 \mathrm{~nm}$ ). Light at these short wavelengths is only present out of the atmosphere and may result extremely harmful to materials misleading the results from the experiments. Second, using a photodiode sensitive to UV A, B, and $C(200-400 \mathrm{~nm})$ the irradiance at the samples located at the center was measured to be $149.6 \mathrm{~W} / \mathrm{m}^{2}$. This irradiance (corresponding obviously to UV A and $B$, since there was not any $C$ ) is equivalent to 3.9 times the $\mathrm{UV} A B$ in the reference spectrum AM1.5D [21]. This concentration ratio together with the fact that the degradation lamp works $24 \mathrm{~h}$ a day provides an acceleration factor of approximately 12 . In other words, the accumulated irradiance at the sample located at the center after 30 days of running test accounts for $107.7 \mathrm{KW} \mathrm{h} / \mathrm{m}^{2}$, which is equivalent to more than a year of outdoor exposure. The UV AB concentration is not uniform across the plane where the samples are located. The useful area of the holder was defined to be a $15 \times 15 \mathrm{~cm}$ square where 18 cuvettes could be placed (Fig. 4). The UV AB concentration remains higher than $109 \mathrm{~W} / \mathrm{m}^{2}(3 \times)$ within the defined useful area. For each fluid under study, four samples were prepared and

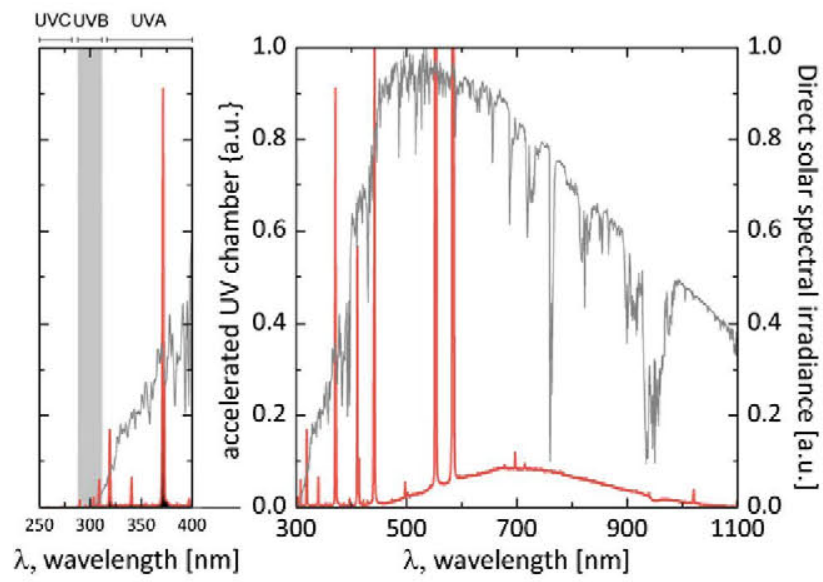

Fig. 3. Spectral distribution at the center of the accelerated UV degradation chamber. For comparison reference direct spectrum AM1.5D [21] is also plotted. they were placed at different locations of the plane. That is, samples of the same fluid were located alternatively at the inner and outer positions to increase confidence in the results.

Several degradation campaigns were carried out. Transmittance measurements were performed after each degradation period lasting 30 days (approximately equivalent to 1 year outdoor exposure). Those samples which showed yellowing (easily detected by visual inspection) and those whose transmittances decreased below $80 \%$ were taken out of degradation chamber. Samples which showed a good performance were introduced again for a new 30 days degradation campaign.

Transmittance of materials optically active in a CPV system must remain high after an outdoor exposure period of 30 years (CPV expected lifetime). However, in the IEC62108 norm [9] the mandatory UV exposure is a cumulative dosage of $50 \mathrm{~kW} \mathrm{~h} / \mathrm{m}^{2}$ which is equivalent to 180 days under outdoor conditions. The 3 years period analyzed in this report fully surpasses the requirements specified in IEC62108 norm. In addition, results support the dosage requirement specified in the norm, as the majority of the degradation mechanisms are revealed within the first equivalent year.

\subsection{Transmittance measurement}

Optical measurements were performed using a visible-nearinfrared spectroradiometer (VIS-NIR-1 SPECTRO 320 from Instruments Systems). Instrument measurement accuracy is $\pm 3 \%$ and reproducibility is $\pm 0.3 \%$ STD. All the optical measurements were performed three times and the mean was calculated. Transmittances were measured from 350 to $1700 \mathrm{~nm}$ for a $5 \mathrm{~nm}$ interval. Fluid samples were contained in high-UV-transmitting PMMA cuvettes during the UV irradiance exposure and to perform the optical measurements. Fresnel losses that take place in the air/PMMA and in the fluid/PMMA interfaces were subtracted, although due to the similarity of the refractive indices the second ones are practically negligible. In other words, transmittance is equivalent to one minus absorption in the fluid sample. For the wavelengths of interest PMMA cuvette absorption is negligible and it has been checked to remain stable after UV exposure. Cuvette interior dimension, that is, optical path through the fluids samples is $10 \mathrm{~mm}$.

\section{Evaluation of transmittance losses}

As current MJ solar cells are composed of three seriesconnected subcells, the effect that transmittance losses may have
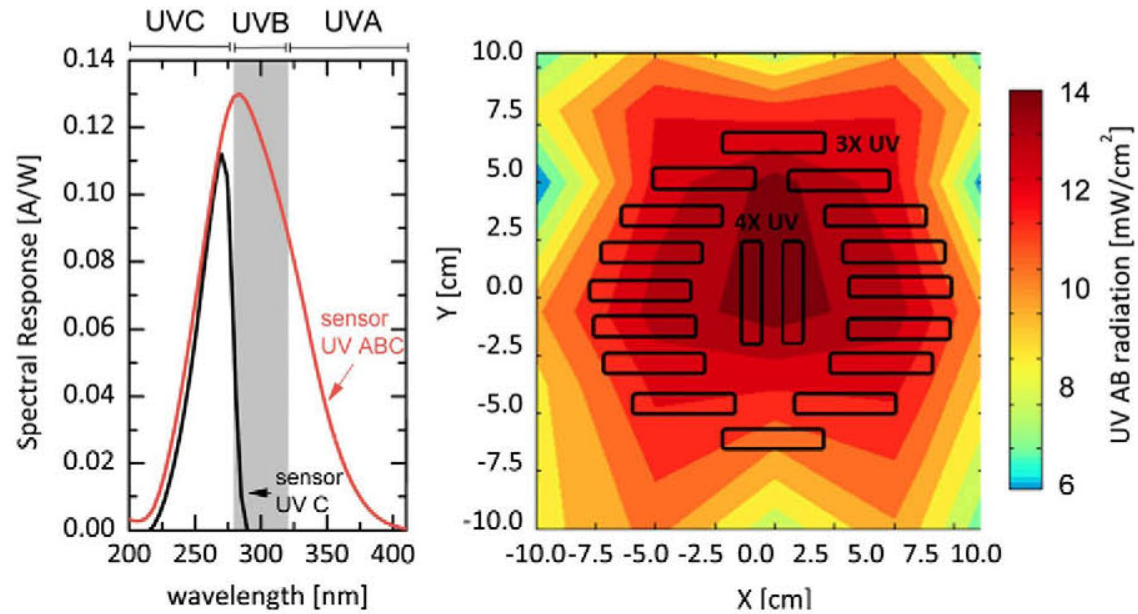

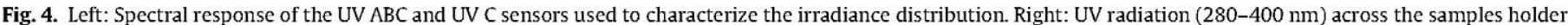
in the UV degradation tests chamber. 
on the power generated by a CPV system is highly dependent on the spectral range where transmittance decreases. As proposed before [26,27], to evaluate the effect of transmittance losses, the photocurrent generated by each subcell when illuminated by the solar spectrum filtered by the fluids transmittance is compared to the photocurrent assuming transmittance unity for all the wavelengths. Data from reference direct normal irradiance spectrum AM1.5D (ASTM G173) [21] is used for the calculation. Quantum efficiency (QE) unity is assumed for each subcell within its corresponding wavelengths range $\left(\lambda_{i}\right.$ to $\lambda_{f}$ ). Relative photocurrent $J_{\text {subcell } i}^{*}$, is calculated as:

$J_{\text {subcelli }}^{*}=\frac{\int_{\lambda_{i}}^{\lambda_{f}} B_{\text {AM1.5D }}(\lambda) T_{\text {material }}(\lambda) \frac{q \lambda}{h c} \delta \lambda}{\int_{\lambda_{i}}^{\lambda_{f}} B_{\text {AM1.5D }}(\lambda)(q \lambda / h c) \delta \lambda} \times 100[\%]$

where $B_{\mathrm{AM} 1.5 \mathrm{D}}(\lambda)$ represents the spectral distribution of the direct normal irradiance AM1.5D; $T_{\text {material }}(\lambda)$, the transmittance of the analyzed material; $q$, the charge of a single electron; $h$, the Planck's constant; and $c$, the speed of light in a vacuum.

Two cell architectures are considered; the first one is the wellknown lattice-matched GaInP/GaInAs/Ge grown over a Ge substrate which has reached a record efficiency of $41.6 \%$ [28]. The second configuration consists in using an epi-growth process over a GaAs substrate and it has shown very promising results obtaining an efficiency of $42.5 \%$ for a GaInP/GaAs/GaInAs solar cell [29] and 43.5\% for the GaInP/GaAs/GaInNAs architecture [30]. To obtain a general result, quantum efficiency equal to one has been assumed for the top subcell (QE between $350-660 \mathrm{~nm}$ ), middle subcell (between 660 and $900 \mathrm{~nm}$ ) and Ge bottom subcell (900-1700 nm). Those wavelengths were assumed for the classical MJ solar cell architecture while for the new design the same top (350-660 nm) and middle (660-900 nm) are considered, but bottom bandgap is enlarged ( $900-1300 \mathrm{~nm})$. In principle, if a MJ cell is current-matched under AM1.5D the power loss will be

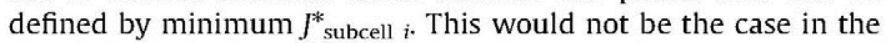
classical latticed-matched design because the $\mathrm{Ge}$ excess of current, but it will be an issue for the new design.

\section{Results}

Fig. 5 summarizes transmittances measured for the fluid samples both before and after UV dosages equivalent to up to 3 years of AM1.5D radiation. As a general rule, transmittance values get worse for shorter wavelengths while they remain unaltered for wavelengths longer than $600 \mathrm{~nm}$. For most of the cases middle and bottom photocurrents remain constant after 1 or 2 yearsequivalent UV exposure whereas, in some cases, top photocurrent decreases significantly (Table 2). Fig. 6 shows the evolution of relative top photogenerated current $J^{*}$ top, this figure being directly related to the power losses that a CPV system would experience due to degradation.

Glycerol and ethylenglycol perform similarly. Initially, they do not transmit light for wavelengths longer than $1400 \mathrm{~nm}$. Because of that, the current photogenerated by the bottom subcell, either in the classic design or in the new one, is considerably lower than top and middle photocurrents. In addition, they show significant yellowing (noticeable by visual inspection after 2 years-equivalent UV dosage). For that degradation period, the yellowing causes the relative top photogenerated current to decrease below $80 \%$. The absorption of light at wavelengths longer than $1400 \mathrm{~nm}$ is caused by the $\mathrm{O}-\mathrm{H}$ bonds within the glycerol and ethylenglycol molecules [22]. For paraffin oils, therminol (synthetic hydrocarbon), and silicone oil, since they do not include $\mathrm{O}-\mathrm{H}$ bonds, the infrared transmittance is much higher. However, there are still significant transmittance valleys,

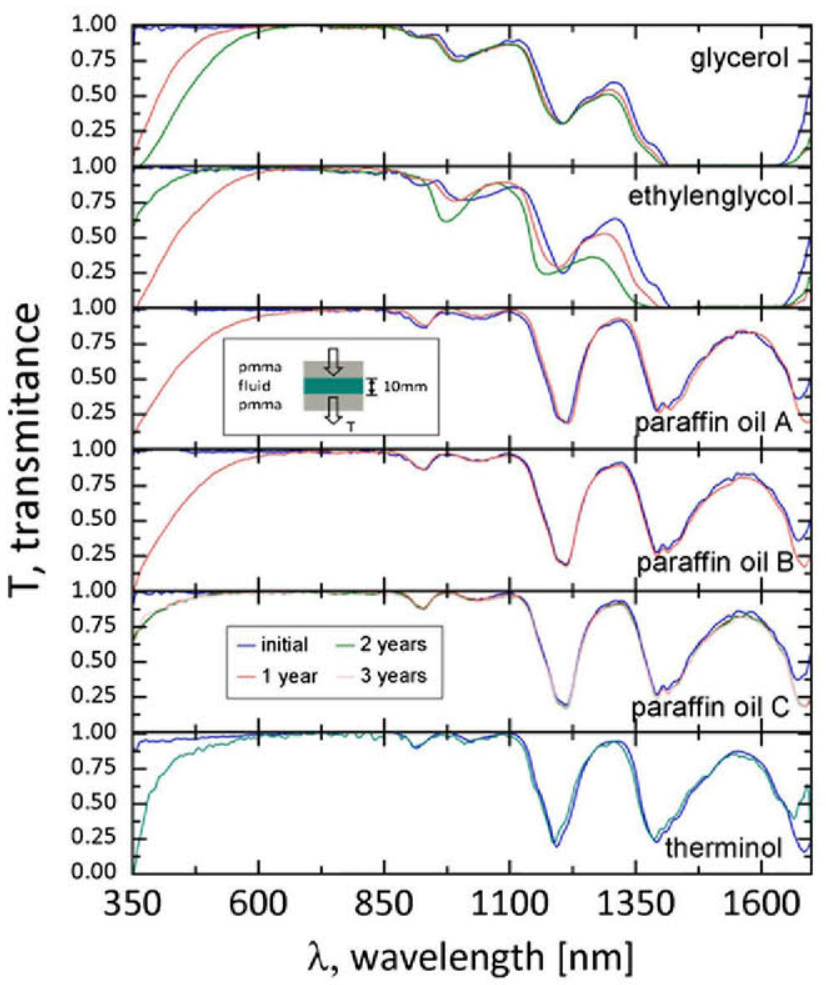

Fig. 5. Transmittance of fluid samples initially and after a UV dosage equivalent to 1-3 years exposed outdoors.

caused by $\mathrm{C}-\mathrm{H}$ bonds [22,31] that will make the new bottom subcell to limit the current if these fluids were used. This is not an issue for the classic bottom subcell since it generates an excess of current under AM1.5D reference spectrum.

Paraffin oil A and B degrade fast under concentrated UV radiation: the relative top photocurrent decreases to $80 \%$ just with a UV dosage equivalent to 1 year. The synthetic hydrocarbon named therminol shows a similar behavior quickly decreasing its transmittance at short wavelengths under UV irradiance.

On the contrary, paraffin oil $\mathrm{C}$ shows a very promising result; its relative top photocurrent decrease to $97 \%$ after a UV dosage equivalent to one year but it remains stable afterwards, up to 3 years. The difference in behavior of paraffin oils A, B, and C may has to do with the procedure employed to obtain them. Probably, the level of impurities in paraffin oils A and B is considerably higher than in oil $\mathrm{C}$, inducing the degradation of those samples.

Although it has not been yet included in the degradation study, another candidate has been selected for its convenient optical properties: silicone oil. This fluid has been used since the beginning of photovoltaics. In fact, the first photovoltaic module built in Bell Laboratories in 1955 included silicone oil to encapsulate and protect the solar cells [32]. Silicone oil showed a very high transmittance for all the wavelengths of interest. This fluid has a chemical composition identical to silicones or polydimethylsiloxane (PDMS), whose reliability and good performance under UV irradiance have already been reported [27,33,34]. PDMS are typically used to optically couple solar cells to SOE. Covalent silicon bonds present in PDMS become increasingly prone to scission for $\lambda<250 \mathrm{~nm}$ (corresponding $\mathrm{Si}-\mathrm{O}$ bond dissociation energy of $451 \mathrm{~kJ} / \mathrm{mol}$ ). On the contrary, covalent carbon bonds in the backbone of hydrocarbons, either paraffin or therminol, become prone to scission for $\lambda<360 \mathrm{~nm}$ (corresponding to $\mathrm{C}-\mathrm{C}$ bond dissociation energy of $347 \mathrm{~kJ} / \mathrm{mol}$ ). Consequently, PDMS are expected to have the greatest thermal and UV stability of all the tested fluids. 
Table 2

Relative photogenerated current for top, middle, classic bottom and new bottom subcells when reference spectrum AM1.5D is filtered by each fluid.

\begin{tabular}{|c|c|c|c|c|c|c|c|c|c|}
\hline & & \multicolumn{2}{|c|}{ Top $(350-660 \mathrm{~nm})$} & \multicolumn{2}{|c|}{ Middle $(660-900 \mathrm{~nm})$} & \multicolumn{2}{|c|}{ Classic bottom $(900-1700 \mathrm{~nm})$} & \multicolumn{2}{|c|}{ Mew bottom $(900-1300 \mathrm{~nm})$} \\
\hline & & $J\left[A \mathrm{~m}^{-2}\right]$ & $J^{*}[\%]$ & $J\left[\mathrm{~A} \mathrm{~m}^{-2}\right]$ & $J^{*}[\%]$ & $J\left[\mathrm{~A} \mathrm{~m}^{-2}\right]$ & $J^{*}[\%]$ & $J\left[\mathrm{~A} \mathrm{~m}^{-2}\right]$ & $J^{*}[\%]$ \\
\hline$T(\lambda)=1$ & & 150 & 100 & 148 & 100 & 233 & 100 & 156 & 100 \\
\hline \multirow[t]{3}{*}{ Glycerol } & Initial & 149 & 99 & 147 & 100 & 121 & 53 & 109 & 70 \\
\hline & 1 year & 134 & 89 & 146 & 99 & 116 & 51 & 105 & 68 \\
\hline & 2 years & 114 & 76 & 147 & 99 & 115 & 50 & 104 & 67 \\
\hline \multirow[t]{3}{*}{ Ethylenglycol } & Initial & 148 & 99 & 143 & 97 & 118 & 51 & 106 & 68 \\
\hline & 1 year & 145 & 97 & 146 & 99 & 116 & 50 & 106 & 68 \\
\hline & 2 years & 119 & 80 & 145 & 98 & 101 & 50 & 93 & 60 \\
\hline \multirow[t]{2}{*}{ Paraffin A } & Initial & 149 & 100 & 146 & 99 & 180 & 78 & 125 & 80 \\
\hline & 1 year & 121 & 81 & 145 & 98 & 178 & 77 & 123 & 79 \\
\hline \multirow[t]{2}{*}{ Paraffin B } & Initial & 149 & 100 & 146 & 99 & 178 & 77 & 123 & 79 \\
\hline & 1 year & 122 & 81 & 145 & 98 & 175 & 75 & 122 & 78 \\
\hline \multirow[t]{4}{*}{ Paraffin C } & Initial & 149 & 100 & 148 & 100 & 182 & 78 & 126 & 81 \\
\hline & 1 year & 145 & 97 & 147 & 100 & 179 & 77 & 125 & 80 \\
\hline & 2 years & 145 & 97 & 147 & 100 & 178 & 77 & 124 & 79 \\
\hline & 3 years & 145 & 97 & 147 & 99 & 178 & 77 & 123 & 79 \\
\hline \multirow[t]{2}{*}{ Therminol } & Initial & 147 & 98 & 148 & 100 & 185 & 80 & 129 & 83 \\
\hline & 1 year & 135 & 90 & 147 & 100 & 183 & 80 & 129 & 83 \\
\hline
\end{tabular}

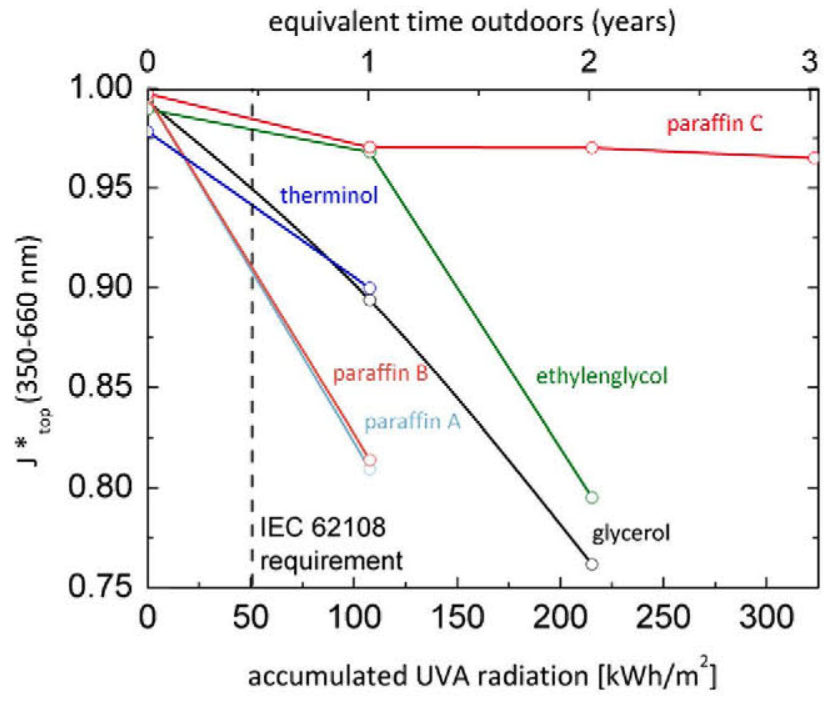

Fig. 6. Evolution of relative top photocurrent as AM1.5D spectrum is filtered by several fluids.

\section{Conclusions}

The optical properties and durability of several dielectric fluids that might be part of concentrating photovoltaic (CPV) systems have been analyzed in this paper. Glycerol and ethylenglycol have been discarded as their low infrared transmittance will create a strong bottom limitation in a system comprising classic multijunction (MJ) solar cells. Additionally they suffered a strong degradation after a UV irradiance dosage equivalent to 2 years exposed outdoors. Two fluids have been identified as suitable to be used on concentrator using MJ solar cells. Both transmit enough light above $850 \mathrm{~nm}$ to prevent bottom subcell limitation. The first one is paraffin oil, but its refine-obtaining process must guarantee a level of sulfur impurities low enough to prevent its degradation under UV exposure. The second one, silicone oil, has the highest transmittance for the wavelengths of interest and has showed to be stable under accelerated UV degradation experiments.

\section{Acknowledgements}

This work has been partially supported by the Spanish Ministry of Education and Science under the FluidReflex 2000 Project and by the European commission within the NACIR project (226409-2) under the VII Framework Program. M. Victoria work is directly supported by Spanish Ministry of Science and Innovation under an FPI grant.

\section{References}

[1] A. Luque, J.M. Gomez Agost, A. Cuevas, J. Eguren E. Lorenzo, Self refrigerating static concentrators for double sided illuminated solar cells, in: Records of the Internal Solar Energy Symposium on Technical Economical and Organizational Aspect, Belgrado, 1978.

[2] M. Victoria, C. Domínguez, High concentrator CPV module based on a single reflective stage immersed in an optical fluid,. Progress in Photovoltaics: Research and Applications, submitted for publication.

[3] X. Han, Y. Wang, L. Zhu, Electrical and thermal performance of silicon concentrator solar cells immersed in dielectric liquids, Applied Energy 88 (12) (2011) 4481-4489.

[4] R. Winston, J.C. Miñano, P. Benítez, Nonimaging Optics, Academic Press, 2005.

[5] T. Ugumori, M. Ikeya, Efficiency increase of solar cells operated in dielectric liquid, Japanese Journal of Applied Physics 20 (1981) 77-80.

[6] Y.A. Abrahamyan, V.I. Serago, V.M. Aroutiounian, I.D. Anisimova, V.I. Stafeev, G.G. Karamian, G.A. Martoyan, A.A. Mouradyan, The efficiency of solar cells immersed in liquid dielectrics, Solar Energy Materials and Solar Cells 73 (4) (2002) 367-375

[7] M.T. Sheldon, C.N. Eisler, H.A. Atwater, GaAs passivation with trioctylphosphine sulfide for enhanced solar cell efficiency and durability, Advanced Energy Materials 2 (3) (2012) 339-344.

[8] Personal communication, REPSOL.

[9] CRC Handbook of Chemistry and Physics, 82nd ed. CRC Press Book.

[10] Datasheet REPSOL.

[11] Datasheet Therminol Solutia.

[12] Datasheet Xiameter PMX-200 Silicone Fluid 5cSt.

[13] Dirac Delta. Science and engineering encycolpedia, www.diracdelta.co.uk.

[14] Data sheet Sigma-Aldrich.

[15] M.J. Weber, Handbook of Optical Materials, CRC Press, 2003.

[16] E.W. Washburn, C.J. West, I. C. of S. Unions, N. A. of S. (U.S.), and N. R. C. (U.S.), International Critical Tables of Numerical Data, Physics, Chemistry and Technology, Index, volumes I-VII, Published for the National Research Council by the McGraw-Hill Book Co, 1930.

[17] A.M. James, M.P. Lord, Macmillan's Chemical and Physical Data, Macmillan, London, 1992

[18] P.R. Cooper, Refractive-index measurements of paraffin, a silicone elastomer and an epoxy resin over the 500-1500 nm spectral range, Applied Optics 21 (19) (Oct. 1982) 3413.

[19] G. Hale, M. Querry, Optical Constants of Water in the $200 \mathrm{~nm}-200 \mu \mathrm{m}$ wavelength region, Applied Optics 12 (3) (Mar. 1973) 555-563. 
[20] C.-B. Kim, C.B. Su, Measurement of the refractive index of liquids at 1.3 and $1.5 \mu \mathrm{m}$ using a fibre optic Fresnel ratio meter, Measurement Science and Technology 15 (9) (Sep. 2004) 1683-1686.

[21] ASTM G173 Standard Tables for Reference Solar Spectral Irradiances, vol. AM15D.

[22] O. Ziemann, P.E. Zamzow, W. Daum, Pof Handbook: Optical Short Range Transmission Systems, Springer, 2008.

[23] D.C. Miller, M.T. Muller, M.D. Kempe, K. Araki, C.E. Kennedy, S.R. Kurtz, Durability of polymeric encapsulation materials for concentrating photovoltaic systems, Progress in Photovoltaic: Research and Applications (2012), p. n/a-n/a

[24] M.D. Kempe, M. Kilkenny, T.J. Moricone, J.Z. Zhang, Accelerated stress testing of hydrocarbon-based encapsulant for medium-concentration CPV applications, in: Proceeding 34rd IEEE Photovoltaic Specialist Conference, Philadelphia, 2009.

[25] K.R. McIntosh, N.E. Powell, A.W. Norris, J.N. Cotsell, B.M. Ketola, The effect of damp-heat and UV aging tests on the optical properties of silicone and EVA encapsulants, Progress in Photovoltaic: Research and Applications 19 (3) (2011) 294-300.

[26] D.C. Miller, M.D. Kempe, C.E. Kennedy, S.R. Kurtz, Analysis of transmitted optical spectrum enabling accelerated testing of CPV designs, in: High and Low Concentrator Systems for Solar Electric Applications IV 2009, 7407, $74070 \mathrm{G}$.
[27] M. Kempe, Overview of scientific issues involved in selection of polymers for PV applications, in: Proceeding 37th IEEE Photovoltaic Specialist Conference, Seattle 2011.

[28] W. Guter, J. Schone, S.P. Philipps, M. Steiner, G. Siefer, A. Wekkeli, E. Welser, E. Oliva, A.W. Bett, F. Dimroth, Current-matched triple-junction solar cell reaching $41.1 \%$ conversion efficiency under concentrated sunlight, Applied Physics Letters 94 (22) (2009) 223504.

[29] S. Wojtczuk, P. Chiu, X. Zhang, D. Derkacs, C Harris, D. Pulver, M. Timmons, InGaP/ GaAs/InGaAs $41 \%$ concentrator cells using bi-facial epigrowth, in: Photovoltaic Specialists Conference (PVSC), 35th IEEE, 2010, pp. 001259-001264.

[30] M.A. Green, K. Emery, Y. Hishikawa, W. Warta, E.D. Dunlop, Solar cell efficiency tables (Version 38), Progress in Photovoltaics: Research and Applications 19 (5) (2011) 565-572.

[31] J.D. Lytle, Handbook of Optics, Vol. II, McGraw-Hill, 1995, chap.34, p.1171.

[32] M.A. Green, Silicon photovoltaic modules: a brief history of the first 50 years, Progress in Photovoltaics: Research and Applications 13 (5) (2005) 447-455.

[33] F. Eltermann, K. Roeder, M. Wiesenfarth, J. Wilde A. Bett, Degradation study on optical materials for concentrator photovoltaics in: Proceedings CPV-8 Toledo, 2012.

[34] D.C. Miller, M.T. Muller, M.D. Kempe, K. Araki, C.E. Kennedy, S.R. Kurtz, Durability of polymeric encapsulation materials for concentrating photovoltaic systems Progress in Photovoltaics: Research and Applications. 2012. 